\title{
A NEW ALGORITHM FOR THE AOD INVERSION FROM NOAA/AVHRR DATA
}

\author{
Lin Sun ${ }^{1}$, Ruibo $\mathrm{Li}^{1 *}$, Huiyong $\mathrm{Yu}^{1}$ \\ ${ }^{1}$ Geomatics College, Shandong University of Science and Technology, Shandong, Qingdao 266590, China
}

TC III, WG III/8

KEY WORDS: AVHRR, AOD, MODIS VI product, NDVI, DDV algorithm

\begin{abstract}
:
The advanced very high resolution radiometer (AVHRR) data from the National Oceanic and Atmospheric Administration satellite is one of the earliest data applied in aerosol research. The dense dark vegetation (DDV) algorithm is a popular method for the present land aerosol retrieval. One of the most crucial steps in the DDV algorithm with AVHRR data is estimating the land surface reflectance (LSR). However, LSR cannot be easily estimated because of the lack of a $2.13 \mu \mathrm{m}$ band. In this article, the moderate resolution imaging spectroradiometer (MODIS) vegetation index product (MYD13) is introduced to support the estimation of AVHRR LSR. The relationship between MODIS NDVI and the AVHRR LSR of the visible band is analysed to retrieve aerosol optical depth (AOD) from AVHRR data. Retrieval experiments are carried out in mid-eastern America. The AOD data from AErosol RObotic NETwork (AERONET) measurements are used to evaluate the aerosol retrieval from AVHRR data, the results indicate that about $74 \%$ of the retrieved AOD are within the expected error range of $\pm(0.05+0.2)$, and a cross comparison of the AOD retrieval results with the MODIS aerosol product (MYD04) shows that the AOD datasets have a similar spatial distribution.
\end{abstract}

\section{INTRODUCTION}

Atmospheric aerosols play a crucial role in the Earthatmosphere system. It can act as cloud condensation nuclei, can greatly influence precipitation and visibility, and its concentration influences the cloud and fog formation in the atmosphere (Zhang et al., 2015; Adesina et al., 2016). Small diameter aerosols, including PM10, PM2.5, and PM0.1, can also affect human health and lead to respiratory diseases (Zheng, 2013). Therefore, effectively supervising and monitoring atmospheric aerosols are especially important in reducing air pollution and improving air quality (Alsaadi et al., 2005).

The National Oceanic and Atmospheric Administration (NOAA) satellite is equipped with the advanced very high resolution radiometer (AVHRR), which is one of the earliest sensors applied in aerosol research. The retrieval of AOD data from AVHRR data is mostly conducted over the ocean. Contrary to the simple properties of the ocean surface, LSR has timevarying complex properties that are influenced by many factors. Therefore, to accurately retrieve AOD, the different surface contributions to the reflectance at the top of atmosphere (TOA) must be effectively distinguished.

\section{AVHRR AOD RETRIEVAL}

The NOAA-19 AVHRR L1B data are pre-processed via radiometric calibration, geometric correction, and cloud detection (Goodrum et al., 2009; Stowe et al., 1991). A new method for LSR estimation to retrieve AOD over land from AVHRR data is proposed based on the MODIS VI product (MYD13), which is used to get an empirical relationship between the LSR of the visible band and NDVI.

Combining with the above conditions, the use of the same NDVI threshold can easily lead to the inaccurate LSR at the regional scale. Under a $10 \mathrm{~km}$ spatial resolution, the atmospheric environment slightly changes, the AVHRR data are divided into $10 \mathrm{~km} \times 10 \mathrm{~km}$ blocks, and the AVHRR NDVI is calculated via the reflectance of the visible and NIR bands of AVHRR, then it is modified by MYD13 NDVI to reduce the influence of the atmosphere via contrast stretching

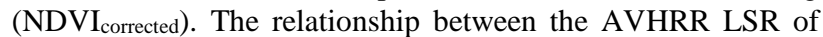
the visible band and NDVI $\mathrm{I}_{\text {corrected }}$ is then fitted based on the LSR estimations. Compared with the DDV algorithm, the AVHRR LSR is no longer a fixed value but rather a dynamic

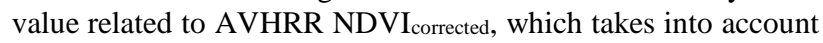
the influence of atmospheric factors as shown below:

$$
\rho_{\text {red }}^{s}=-0.1415 \times N D V I+0.1548 \text {. }
$$

Based on this model (Eq. (1) and Figure 1), an AOD retrieval is performed in mid-eastern America from June to October 2016.

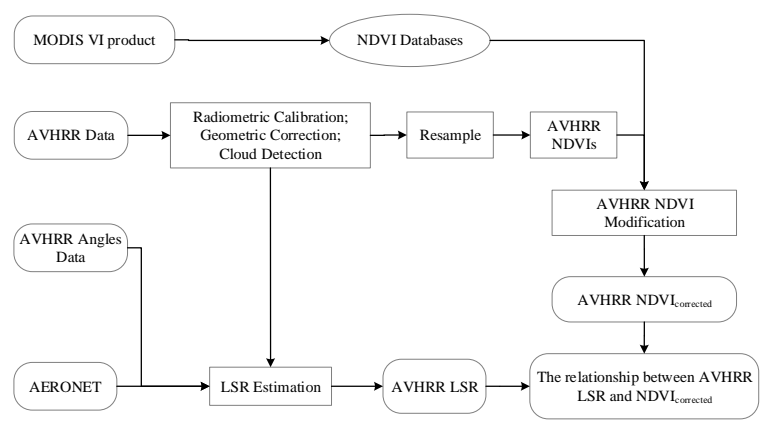

Figure 1. Flow chart of the AVHRR LSR determination model

* Corresponding author - 1rb0106@hotmail.com 


\section{COMPARISON AND VALIDATION}

\subsection{Validation with the MODIS Aerosol Product}

The MYD04 C6 with a $3 \mathrm{~km}$ spatial resolution, which is the closest to the surface type considered in this paper, is mainly applied to the DDV algorithm. Therefore, the MYD04 C6 (3 km) is used to validate the results.

The AVHRR AOD and MYD04 AOD from June to October are shown in Figure 2 (such as September). The result at $0.64 \mu \mathrm{m}$ over many areas is lesser than 0.5 . Combined with MYD13, some areas with a high AOD have a small NDVI. These findings are similar to those obtained by previous studies (Xue et al., 2017). In addition, AVHRR AOD and MYD04 AOD apply different cloud detection algorithms, while the AVHRR data lack mature algorithms and products. MYD04 AOD has a higher inversion range and a more continuous spatial distribution than AVHRR AOD.
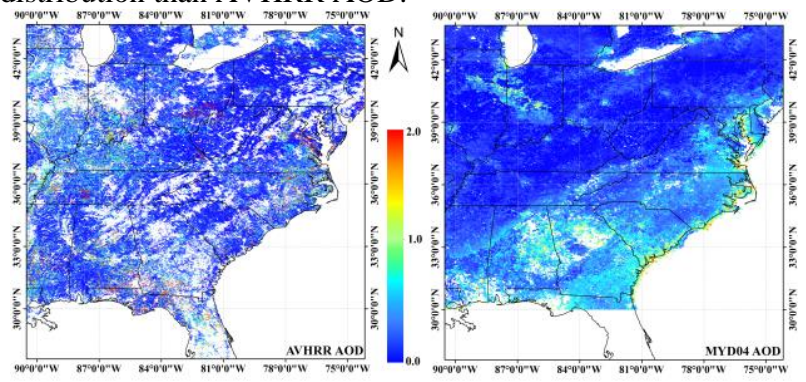

(a) Monthly average of 09/2016

Figure 2 Monthly AOD from AVHRR AOD and MYD04. a) AVHRR AOD and b) MYD04 C6 DDV algorithm.

\subsection{Validation with AERONET}

To further evaluate the inversion algorithm, 10 AERONET sites are selected for verification. AERONET is a global network of ground-based sun/sky radiometers that mainly measures surface AOD, which is mainly used for evaluating the AOD retrieval results.

Figure 3 compares the regression analysis results for AVHRR AOD with the AERONET measurements at 10 sites, where the black dashed lines represent the error lines of MYD04 (Chu et al., 2002). Given that the retrieved pixels are clear pixels over the vegetated areas, the AVHRR AOD and AERONET measurements are generally small, $74 \%$ of the collections are below the error lines, and the RMSE is less than 0.1. The retrieved AVHRR data are slightly higher than the AERONET measurements. The $R^{2}$ is 0.4212 , thereby indicating a strong correlation and a high retrieval accuracy. However, overestimation tends to occur when the AVHRR AOD is greater than 0.1 .

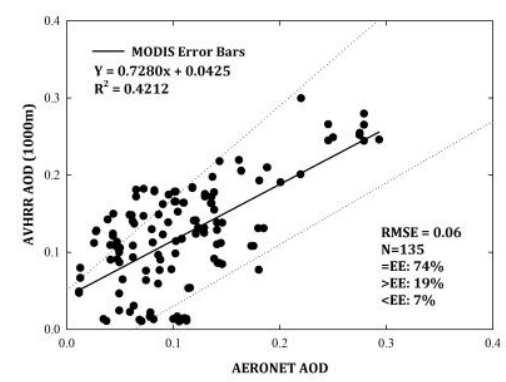

Figure 3 Retrieval results of AERONET measurements and AVHRR AOD

\section{CONCLUSIONS}

An algorithm for retrieving AOD over land from AVHRR data is constructed based on MODIS VI. This algorithm is applied in mid-eastern America from June to October 2016. First, the NOAA-19 AVHRR L1B data are preprocessed by the proposed calibration parameters and methods, and the CLAVR algorithm is used to obtain the AVHRR cloud mask. Second, based on MYD13 NDVI, LSR and NDVI are used to construct a statistical model for the relationship between AVHRR LSR and

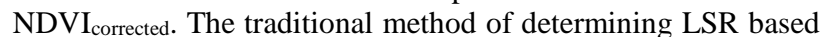
on experience is also improved. The algorithm is also applied in mid-eastern America, and the AOD of vegetated areas is retrieved. The AOD retrieval results show an agreement between AVHRR AOD and MYD04 AOD as well as reveal an obvious correlation between AVHRR AOD and AERONET data.

\section{REFERENCES}

Adesina, A.J., Kumar, K.R. and Sivakumar, V., 2016. AerosolCloud-Precipitation Interactions over Major Cities in South Africa: Impact on Regional Environment and Climate Change. Aerosol Air Qual. Res., 16(1), pp. 195-195.

Alsaadi, J., Szykman, J., Pierce, R.B., Kittaka, C., Neil, D., Chu, D.A., Remer, L., Gumley, L., Prins, E. and Weinstock, L., 2005. Improving National Air Quality Forecasts with Satellite Aerosol Observations. Bull. Amer. Meteor. Soc., 86(9). pp. 1249-1261.

Chu, D.A., Kaufman, Y.J., Ichoku, C., Remer, L.A., Tanré, D. and Holben, B.N., 2002. Validation of MODIS aerosol optical depth retrieval over land. Geophys. Res. Lett., 29(12). pp. $1617-1621$.

Goodrum, G., Kidwell, K.B. and Winston, W., 2009. NOAA KLM User's Guide with NOAA-N, -N'Supplement, February 2009 revision. NC: NOAA NESDIS NCDC, Asheville.

Stowe, L.L., McClain, E.P., Carey, R., Pellegrino, P., Gutman, G.G., Davis, P., Long, C. and Hart, S., 1991. Global distribution of cloud cover derived from NOAA/AVHRR operational satellite data. Adv. Space Res., 11(3). pp. 51-54.

Xue, Y., He, X., Leeuw, G. D., Mei, L., Che, Y., Rippin, W., Guang, J. and Hu, Y., 2017. Long-time series aerosol optical depth retrieval from AVHRR data over land in North China and Central Europe. Remote Sens. Environ., 198. pp. 471-489.

Zhang, D., Xu, C., Duan, J., Wang, Y., Du, J., Zha, S., Leng, C., Li, X., Cheng, T., Tao, J. and Zhang, R., 2015. Inter-annual variations of cloud and precipitation and their possible relationships with surface aerosols in shanghai. Aerosol Air Qual. Res., 15(4). pp. 1367-1379.

Zheng, J., 2013. Analysis of Spatial and Temporal Variability of PM10 Concentrations Using MODIS Aerosol Optical Thickness in the Pearl River Delta Region, China. Aerosol Air Qual. Res., 13(3). pp. 862-876.

Revised October 2017 